Vol 10, Issue 11, 2017

\title{
ACUTE TOXICITY TESTING OF NEWLY DISCOVERED POTENTIAL ANTIHEPATITIS B VIRUS AGENTS OF PLANT ORIGIN
}

\begin{abstract}
SUBAIEA GM ${ }^{1}$, ALJOFAN M ${ }^{2 *}$, DEVADASU VR ${ }^{2}$, ALSHAMMARI TM ${ }^{2,3}$
${ }^{1}$ Department of Pharmacology and Toxicology, College of Pharmacy, University of Hail, Kingdom of Saudi Arabia. ${ }^{2}$ Department of Clinical Pharmacy, College of Pharmacy, University of Hail, Kingdom of Saudi Arabia. ${ }^{3}$ Department of ???, Medication Safety Research Chair, King Saud University, Riyadh, Saudi Arabia. Email: m.aljofan@gmail.com
\end{abstract}

Received: 15 June 2017, Revised and Accepted: 25 July 2017

ABSTRACT

Objective: Our previous studies indicate that alkaloids could be developed as potential antihepatitis B agents. In the present study, we investigated the in vitro antihepatitis B virus (HBV) activity and in vivo acute oral toxicity of three isoquinoline alkaloids [-(-) Canadine, Corydadine, and Berberine] obtained from Fumaria and Corydalis species. The compounds were selected based on their therapeutic indexes calculated previously in vitro.

Methods: The antiviral activity and cytotoxicity of selected isoquinoline alkaloids were evaluated in vitro in HepG2 cells. In vivo, acute oral toxicity was performed in female mice following the Organization for Economic Cooperation and Development test guideline-423 (acute toxicity class method).

Results: The selected agents have shown high antiviral activity against HBV and low cytotoxicity in vitro. The results obtained from an acute oral toxicity study revealed that the $\mathrm{LD}_{50}$ of all the test compounds was $>2000 \mathrm{mg} / \mathrm{kg}$ when administered orally to mice. All the tested compounds fall under the category 5 (unclassified) according to the Globally Harmonized System, with a $\mathrm{LD}_{50}$ value $>2000 \mathrm{mg} / \mathrm{kg}$ when orally administered to mice.

Conclusion: The results of the study revealed that OR-13 and MNAD can be studied further and can be developed as antihepatitis B drugs.

Keywords: Hepatitis B virus, Isoquinoline alkaloids, Antiviral, Cytotoxicity, Acute toxic class method, Organization for Economic Cooperation and Development 423.

(C) 2017 The Authors. Published by Innovare Academic Sciences Pvt Ltd. This is an open access article under the CC BY license (http://creativecommons. org/licenses/by/4. 0/) DOI: http://dx.doi.org/10.22159/ajpcr.2017.v10i11.20717

\section{INTRODUCTION}

There is no cure for individuals with chronic Hepatitis B virus (HBV) infections. Chronic infections are associated with cirrhotic liver failure, and infected individuals have an increased risk of developing hepatocellular carcinoma [1,2]. Interferon-alpha (IFN- $\alpha$ ) is used for the treatment of chronic HBV infections; it has immunomodulatory, antiviral, and antiproliferative effects. IFN- $\alpha$ has limited efficacy in patients with certain characteristics such as high serum HBV DNA levels, childhood infection, decompensated liver disease, immunosuppression due to disease or therapy, male sex, mild-to-moderate liver disease, and Asian ethnicity. Patients with these characteristics comprise approximately $70 \%$ of the HBV-infected population. In addition, IFN- $\alpha$ therapy is associated with adverse effects that often necessitate dose reduction or discontinuation $[3,4]$. Therapy with antiviral compounds for HBV infections has focused primarily on a strategy of inhibiting viral polymerase. The nucleoside analogue, lamivudine (LMV) has been used for the treatment of chronic HBV infection for more than a decade, but the effectiveness of long-term LMV treatment therapy is compromised by the emergence of LMV-resistant HBV [4,5]. A number of other nucleoside/nucleotide analogues including adefovir dipivoxil, entecavir, telbivudine, and, most recently, tenofovir disoproxil fumarate have been developed and approved for HBV treatment [6-8]. However, long-term treatment of chronic HBV infection with nucleos(t)ide analogs can lead to the emergence of HBV-resistant mutants of the polymerase gene [9]. The development of nonnucleoside compounds is highly warranted to overcome the problem with drug-resistance mutants and to provide a long-term durable virological effect, leading to serological, biochemical, and histological benefits, most likely achievable by applying a combination therapy including different classes of compounds.

Alkaloids represent the largest single class of plant secondary metabolites. Many alkaloids are used in therapeutics and as pharmacological tools [10]. A wide range of biological effects has been reported for alkaloids including emetic, anticholinergic, antitumor, diuretic, sympathomimetic, antiviral, antihypertensive, hypnoanalgesic, antidepressant, myorelaxant, antitussive, antimicrobial, and antiinflammatory activities [11]. We have screened a number of isoquinoline alkaloids in vitro against $\mathrm{HBV}$ and resulted in the identification of three (Rib, OR-13, and MNAD; Fig. 1) potentially novel anti-HBV agents [12]. The objective of the current study was to move the newly discovered agents into the drug discovery pipeline and prepare them for further animal study. In our present study, we aim to assess anti-HBV activity, cytotoxicity, and acute oral toxicity in mice of the three agents. We isolated these compounds in large quantities to cover the entire study and tested their acute oral toxicity in rodents, which are an important part of the drug discovery process.

\section{METHODS}

Extraction and purification of alkaloids

Isoquinoline alkaloids were obtained from 16 Fumaria and six Corydalis species growing in Turkey. The taxonomic identification of each plant species was confirmed by a local plant taxonomist in the Hail city, and plant specimens have been deposited at the College of Pharmacy, University of Hail, and Kingdom of Saudi Arabia. The plant materials were dried in the shade, dissected, powdered, and weighed accurately and isolated, purified, and characterized as described elsewhere [12].

\section{In vitro drug screening}

Antiviral activity of Rib, OR-13, and MNAD was determined using the human hepatoma cell line HepG2.2.15, which constitutively expresses HBV [13]. The process was described in our previous report [2]. Briefly, cells were seeded at a density of $\left(2 \times 10^{4}\right)$ into individual wells of 96-well microtiter plates and incubated at $37^{\circ} \mathrm{C}$ overnight in Dulbecco's modified Eagle's medium supplemented with GlutaMax ${ }^{\mathrm{TM}}$ (Invitrogen) 




Fig. 1: Chemical structures of the isolated compounds. (a) RIB (-[-] Canadine), (b) OR 13 (Corydadine), (c) MNAD (Berberine)

and $10 \%$ GIBCO fetal bovine serum (Invitrogen). The medium was discarded, and $100 \mu \mathrm{l}$ of serial log dilutions of different test compounds were added to each well in triplicates (concentration range, $10 \mu \mathrm{M}$ to $100 \mathrm{pM}$ ). Cells were incubated in the presence of the three agents for $2 \mathrm{~h}$, and the medium was then collected and screened for potential reductions in HBsAg antigen using a MONOLISA ${ }^{\mathrm{TM}}$ Anti-HBs EIA kit (Bio-Rad) $(\mathrm{n}=4)$. The $\mathrm{IC}_{50}$ (concentration resulting in $50 \%$ inhibition) values were calculated.

\section{Measurement of cytotoxicity}

The compounds were evaluated for their cytotoxicity using a CellTiterGlo cytotoxicity kit (Promega) according to the manufacturer's instructions and methods described earlier [14]. The CellTiterGlo luminescent cell viability assay is a homogeneous method of determining the number of viable cells in culture based on quantitation of the ATP present, which signals the presence of metabolically active cells. Briefly, HepG2 cell monolayers in 96-well plates were incubated overnight at $37^{\circ} \mathrm{C}$ with $200 \mu \mathrm{l}$ of serial log dilutions of each compound $(n=4)$ in DMEM. The medium was removed, and $100 \mu$ lof CellTiter-Glo Reagent was added to each well, mixed well to lyse cells, equilibrated to room temperature for $10 \mathrm{~min}$, and then read using a luminometer. The $\mathrm{CC}_{50}$ (concentration resulting in $50 \%$ cytotoxicity) values were calculated.

\section{Experimental animals}

Swiss albino mice, weighing (18-22), were obtained from the Department of Pharmacology and Toxicology, College of Pharmacy, University of Hail, Kingdom of Saudi Arabia. All the animals were housed in groups of $(n=3 /$ cage) in standard plastic cages with wood chips as bedding material. All mice were maintained at room temperature, $30-70 \%$ relative humidity, $12 \mathrm{~h}$ light/dark artificial photoperiod. All mice were fed with commercially available rodent pellet feed and purified water ad libitum. The cages and bedding material were changed weekly once. All mice were acclimatized for not $<5$ days and were randomly assigned to test groups (Group 1-3) and vehicle control groups (Group 4). The study protocol was approved by the Institutional Animal Ethics Committee of the University of Hail, Kingdom of Saudi Arabia, Reference No. 0150014/2015.

\section{Acute oral toxicity study}

Acute oral toxicity study was performed on the three (Rib, OR-13, and MNAD) agents using female mice following the Organization for Economic Cooperation and Development (OECD) acute toxic class (ATC) method test guideline-423 [15,16]. Four groups, each group consisted of six mice ( $\mathrm{n}=3 / \mathrm{step}$ ) was used. Group I-III received $2000 \mathrm{mg} / \mathrm{kg}$ body weights of different agents orally, while Group IV was used as a control and received corn oil $(10 \mathrm{ml} / \mathrm{kg})$. All the treatments were made using a glass syringe fitted with an oral gavage (1.5 inches in length, straight tube with a $2.4 \mathrm{~mm}$ rounded tip). The mortality and clinical signs of toxicity were observed in animals for the first $24 \mathrm{~h}$, and thereafter, once daily for 14 days. On day 15 , animals were euthanized under light anesthetic ether anesthesia and gross pathology of internal organs was observed. Depending on the mortality of animals, the test procedure was followed as per the annexure $2 \mathrm{~d}$ of OCED 423 test guidelines [17].

\section{Statistical analysis}

The values are expressed as mean \pm SD. The nonlinear regression analysis was performed using GraphPad Prism software to determine the $\mathrm{IC}_{50}$ and $\mathrm{CC}_{50}$ values.

\section{RESULTS}

The in vitro antihepatitis activity of Rib was lower than the OR-13 and MNAD, and their results are shown in Fig. 2. The cytotoxicities of the agents were similar and are shown in Fig. 3 . The $\mathrm{IC}_{50}$ values for all the agents were similar and were $21 \mathrm{mg}, 15 \mathrm{mg}$, and $23 \mathrm{mg}$, respectively, for Rib, OR-13, and MNAD. CC ${ }_{50}$ values were also similar and were $63 \mathrm{mg}$, $78 \mathrm{mg}$, and $89 \mathrm{mg}$, respectively, for Rib, OR-13, and MNAD. However, OR-13 has shown a broader therapeutic index over other agents when compared (Table 1).

In an acute oral toxicity study, the Rib-treated mice looked slightly irritated (after $4 \mathrm{~h}$ of exposure). They were licking their forepaws. Few animals showed erythema around the nose and were found to be lethargic (Table 2) compared to vehicle-treated animals until $24 \mathrm{~h}$ of observation. All these effects were not seen in all the Rib-treated animals after $24 \mathrm{~h}$ of treatment till the completion of the study. In all the treatment groups, at necropsy, gross pathological observation of all internal organs showed normal appearance by visual observation except, lungs of Rib-treated mice. Petechial hemorrhages were observed in the lungs of two animals in the Rib-treated animals $(n=1$, step 1) and not seen with animals in step 2 . These findings may be attributed due to the inhalational effects of anesthetic ether as evidenced from the previous historical laboratory gross pathological data of lungs. However, mice of other groups (OR-13, MNAD, and control) did not show any abnormal clinical signs of toxicity. The stools were observed to be soft in all the treatment groups and might be attributed due to corn oil. These effects were not observed in all the groups after $24 \mathrm{~h}$ of their respective treatments. In all the treatment 
Table 1: Therapeutic index of Rib, OR-13, and MNAD

\begin{tabular}{llll}
\hline Compound & $\mathbf{I C}_{\mathbf{5 0}} \mathbf{( m g )}$ & $\mathbf{C C}_{\mathbf{5 0}} \mathbf{( m g )}$ & Therapeutic index \\
\hline Rib & 21 & 63 & 3 \\
OR-13 & 15 & 78 & 5.2 \\
MNAD & 23 & 89 & 3.9 \\
\hline
\end{tabular}

Table 2: Observations on behavior of mice after different treatments

\begin{tabular}{lllll}
\hline Duration (h) & Rib & OR-13 & MNAD & Control \\
\hline 4 & Irritated & Normal & Normal & Normal \\
8 & $\begin{array}{l}\text { Licking their } \\
\text { forepaws }\end{array}$ & Normal & Normal & Normal \\
& Erythema of nose & Normal & Normal & Normal \\
12 & Lethargic & Normal & Normal & Normal \\
16 & Lethargic & Normal & Normal & Normal \\
24 & & & & \\
\hline
\end{tabular}



Fig. 2: In vitro antihepatitis B activity of Rib, OR-13, and MNAD

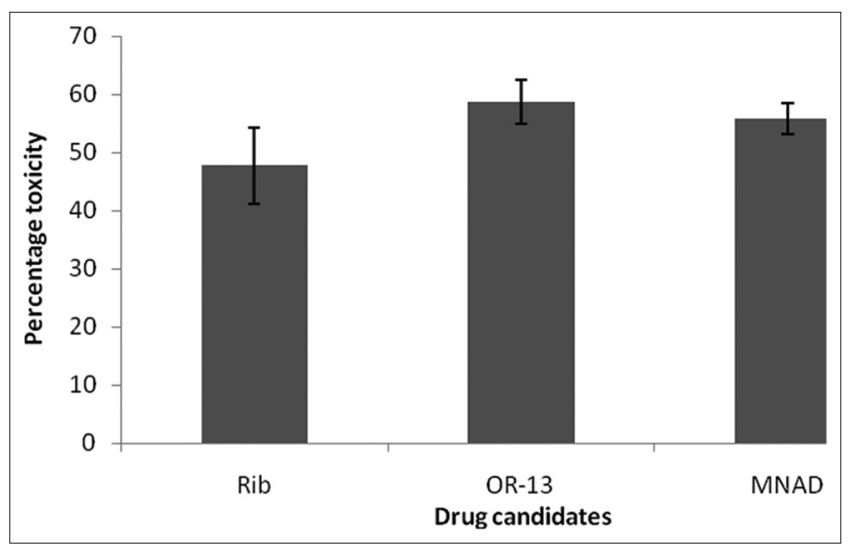

Fig. 3: Cytotoxicity of Rib, OR-13, and MNAD

groups, the animals exhibited normal behavior after $24 \mathrm{~h}$ of treatment, and there was no treatment-related mortality until the study was completed. In our study, we observed that there was no treatment mortality up to $24 \mathrm{~h}$ of treatment. Hence, we dosed another set (step 2) of animals ( $\mathrm{n}=3$ /group) after $24 \mathrm{~h}$ and experimented them similar to step 1 animals. The $\mathrm{LD}_{50}$ value is considered to be $>2000 \mathrm{mg} / \mathrm{kg}$ for OR-13, MNAD, and Rib and is classified as orally safe as per Globally Harmonized Classification System for Chemical Substances and Mixtures described in OECD guideline-423 (annexure 2d).

\section{DISCUSSION}

Drug discovery is an essential part of drug development. Drugs can be identified from natural sources and then isolated, purified, and modified to suit the requirements or else they can be synthesized from a lead molecule [18]. Toxicological screening is an essential part of the drug discovery process as the drug molecule is intended to provide very low toxicity and high therapeutic efficacy that are calculated as the therapeutic index. Preclinical toxicity studies are carried out in cell lines and or experimental animals. The United States Food and Drugs Administration make it essential to screen the new drug molecules for the pharmacological activity and toxicology in animal models. Some toxicity tests are mostly used to screen drugs for specific endpoints such as cancer, cardiotoxicity, or skin/eye irritation. ATC method predicts the lethality dose range and possible clinical signs of toxicity on single oral administration of the test substance. Acute toxicity studies in animals are carried out for any drug intended for human use. These studies will identify the toxicity of any specific organ after acute exposure of the test substance. These studies if carried out on a lead molecule will identify the starting dose that can be used in human studies. These studies will also be able to identify the lethal dose of a drug in terms of $\mathrm{LD}_{50}$ (the dose that can kill $50 \%$ of the animals). These acute toxicity studies can be carried out following methods such as Lorke's method [19] and Karber's method [20].

Calculation of $\mathrm{LD}_{50}$ involves a high ratio of mortality and excess number of animals. Thus, alternative approaches are used to understand acute toxicity. These include the fixed dose procedure (FDP), the ATC method, and the up and down (UDP) method. The FDP assesses the nonlethal toxicity rather than the lethal dose [21]. The investigational compound is administered at fixed dose levels of 5, 50,500, and $2000 \mathrm{mg} / \mathrm{kg}$ and the animal is observed for a defined period. The ATC method is a sequential procedure wherein three animals of the same sex are used in every step [20]. The UDP testing method is the toxicological testing approach most recommended by various regulatory agencies because this method reduces the number of vertebrate animals in research. This method involves dosing single animals sequentially at $48 \mathrm{~h}$ intervals [22]. Female rodents are preferable for UDP testing. A dose less than the best estimate lethal dose is selected and administered to an animal, and the animal is observed for $48 \mathrm{~h}$. If it survives, the study is continued with a higher dose (twice the original dose); if the animal dies, testing is conducted with a lower dose with another animal of the same sex as the original animal and is limited to doses up to $2000 \mathrm{mg} / \mathrm{kg}$.

In 1996, the Center for Drug Evaluation and Research suggested a single dose acute toxicity testing procedure for pharmaceutical substances. This procedure uses a fixed safe dose that should not cause adverse events or threaten the life of the animal. The experiment must be carried out with a minimum of two mammalian species, including a nonrodent species, and the animals must be observed for 14 days [13].

The drugs screened for activity in the present study showed good therapeutic potential to be developed as antihepatitis B drugs. All the three drugs showed activity at similar concentrations. The cytotoxicity of OR-13 was lower when compared to other two drug candidates resulting in broader therapeutic index. These drugs were also tested for antibiotic activity; however, they showed no such activities in antibiotic film assay. Anti-HBV activities warranted animal studies for toxicity screening.

Drug Rib showed acute toxicity in mice and affected the lungs especially. We have observed black spots on the lungs of two mice that indicate the toxicity of Rib. However, the other two drugs OR-13 and MNAD showed neither harmful effect in animal behavior nor their key organs including lungs, heart, liver, and kidneys, as they were similar in appearance to the control group mice' organs. From our studies, we conclude that Rib is toxic and OR-13 and MNAD are safe and can be tested further. Rib can be structurally modified to produce lower toxicity.

\section{CONCLUSION}

Selected three agents in our study showed antihepatitis activity. However, Rib showed toxicity in acute animal studies. OR-13 and MNAD can be studied further and can be developed as antihepatitis B drugs. 


\section{ACKNOWLEDGMENT}

The authors thank the University of Hail, for supporting this research by the awarded grant No. 0150014 provided by Deanship of Scientific Research.

\section{REFERENCES}

1. Agarwal N, Naik S, Aggarwal R, Singh H, Somani SK, Kini D, et al. Occult hepatitis B virus infection as a cause of cirrhosis of liver in a region with intermediate endemicity. Indian $\mathrm{J}$ Gastroenterol 2003;22:127-31.

2. Lewis S, Roayaie S, Ward SC, Shyknevsky I, Jibara G, Taouli B. Hepatocellular carcinoma in chronic hepatitis $\mathrm{C}$ in the absence of advanced fibrosis or cirrhosis. AJR Am J Roentgenol 2013;200:W610-6.

3. Sun P, Yang X, He RQ, Hu QG, Song ZF, Xiong J, et al. Antiviral therapy after curative treatment of hepatitis $\mathrm{B} / \mathrm{C}$ virus-related hepatocellular carcinoma: A systematic review of randomized trials. Hepatol Res 2014;44:259-69.

4. Idilman R, Cinar K, Seven G, Bozkus Y, Elhan A, Bozdayi M, et al. Hepatitis B surface antigen seroconversion is associated with favourable long-term clinical outcomes during lamivudine treatment in $\mathrm{HBeAg-}$ negative chronic hepatitis B patients. J Viral Hepat 2012;19:220-6.

5. Li SY, Qin L, Zhang L, Song XB, Zhou Y, Zhou J, et al. Molecular epidemical characteristics of lamivudine resistance mutations of HBV in southern China. Med Sci Monit 2011;17:PH75-80.

6. Han Y, Zhang Y, Mei Y, Wang Y, Liu T, Guan Y, et al. Analysis of hepatitis $\mathrm{B}$ virus genotyping and drug resistance gene mutations based on massively parallel sequencing. J Virol Methods 2013;193:341-7.

7. McGonigal KH, Bajjoka IE, Abouljoud MS. Tenofovir-emtricitabine therapy for the prevention of hepatitis B recurrence in four patients after liver transplantation. Pharmacotherapy 2013;33:e170-6.

8. Jenh AM, Pham PA. Tenofovir disoproxil fumarate in the treatment of chronic hepatitis B. Expert Rev Anti Infect Ther 2010;8:1079-92.

9. Billioud G, Pichoud C, Puerstinger G, Neyts J, Zoulim F. The main hepatitis $\mathrm{B}$ virus (HBV) mutants resistant to nucleoside analogs are susceptible in vitro to non-nucleoside inhibitors of HBV replication. Antiviral Res 2011;92:271-6.
10. Souto AL, Tavares JF, da Silva MS, Diniz Mde F, de Athayde-Filho PF, Barbosa Filho JM. Anti-inflammatory activity of alkaloids: An update from 2000 to 2010. Molecules 2011;16:8515-34.

11. Aiello A, Fattorusso E, Imperatore C, Irace C, Luciano P, Menna M, et al. Zorrimidazolone, a bioactive alkaloid from the non-indigenous mediterranean stolidobranch Polyandrocarpa zorritensis. Mar Drugs 2011;9:1157-65

12. Aljofan M, Netter HJ, Aljarbou AN, Hadda TB, Orhan IE, Sener B, et al. Anti-hepatitis B activity of isoquinoline alkaloids of plant origin. Arch Virol 2014;159:1119-28.

13. Sells MA, Zelent AZ, Shvartsman M, Acs G. Replicative intermediates of hepatitis B virus in HepG2 cells that produce infectious virions. J Virol 1988;62:2836-44.

14. Hamid HA, Yahaya IH. Cytotoxicity of Clinacanthus nutans extracts on human hepatoma (HEPG2) cell line. Int J Pharm Pharm Sci 2016;8:293-5

15. Kesavanarayanan KS, Sathiya S, Kalaivani P, Ranju V, Sunil AG, Saravana Babu C, et al. DIA-2, a polyherbal formulation ameliorates hyperglycemia and protein-oxidation without increasing the body weight in Type II diabetic rats. Eur Rev Med Pharmacol Sci 2013; 17:356-69.

16. Santosh NB, Pravin DC. Acute and sub-acute oral toxicity assessment of the polyherbal formulation in albino wister rats. Int J Pharm Pharm Sci 2016;8:311-6.

17. OECD Guidelines for the Testing of Chemicals and Section 4: Health Effects Test No. 423: Acute Oral Toxicity-Acute Toxic Class Method. Paris: OECD Publishing; 2002.

18. Monga M, Sausville EA Developmental therapeutics program at the NCI: Molecular target and drug discovery process. Leukemia 2002;16:520-6.

19. Lorke D. A new approach to practical acute toxicity testing. Arch Toxicol 1983;54:275-87.

20. Chinedu E, Arome D, Ameh FS. A new method for determining acute toxicity in animal models. Toxicol Int 2013;20:224-6.

21. Parasuraman S. Toxicological screening. J Pharmacol Pharmacother 2011;2:74-9.

22. Bruce RD. An up-and-down procedure for acute toxicity testing. Fundam Appl Toxicol 1985;5:151-7. 